216

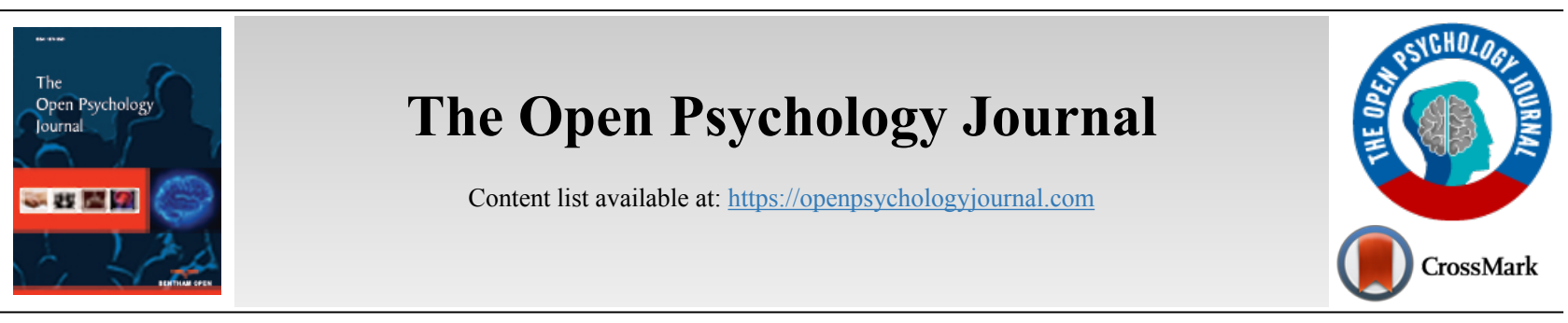

RESEARCH ARTICLE

\title{
Impression Management within Instagram Stories: A Phenomenological Study
}

\author{
Vidi Sukmayadi, ${ }^{1, *}$ and Azizul Halim Yahya ${ }^{2}$ \\ ${ }^{1}$ Communications Department, Universitas Pendidikan Indonesia, Bandung, Indonesia \\ ${ }^{2}$ Faculty of Communication and Media Studies, Universiti Teknologi Mara, Shah Alam, Malaysia
}

\begin{abstract}
:
Objective:

This study is aimed at exploring the motivation and impression management strategies of "Instagram Stories" users.

Materials and Methods:

The authors interviewed 30 Instagram influencers in updating their contents on the Instagram Stories feature. Semi-structured interviews were conducted to capture the informants' experience and consciousness in producing their online content as a part of their impression management.

Results:

The main findings of the study were as follows; First, Self-existence, viewers' attractiveness, and innovativeness of the application have become the core motivation for the users in choosing the Instastory feature. Secondly, the impression management applied by the users as their front stage lies in the construction of their uploaded contents. Lastly, the users of Instagram Stories constructed their content in the form of thematic consistency, uniqueness, "captions" and information (image) editing.

Conclusion:

The present study indicated that the impression management pattern in using Instagram stories had become an integral part of the uploaded content to fulfil the users' highest self-satisfaction and maximum impacts on the viewers as well as their virtual followers.
\end{abstract}

Keywords: Impression management, New media, Instagram, Psychological communication, Social media, Captions.

\begin{tabular}{|l|l|l|l|}
\hline Article History & Received: September 10, 2019 & Revised: November 27, 2019 & Accepted: December 11, 2019
\end{tabular}

\section{INTRODUCTION}

It is inarguable that social media has become a part of the majority of the population in the world. Recorded data by Statista [1] showed that social media have been connecting more than two billion of the world citizen. The number of social media users is even predicted to keep increasing and generating a higher dependency and consequential bond towards social media usage [2].

The same case goes to the development of social media in Indonesia, which has been rapidly increasing. In 2014, Indonesia was known as "The Capital City of Social Media" since the number of social media users, and the rate of its active users was very high [3]. The current number of social media users in the country has reached 9609 million people

\footnotetext{
* Address correspondence to this author at the Communications Department, Faculty of Social Science Education, Universitas Pendidikan Indonesia Jl. Dr. Setiabudhi 229, Bandung, 40154, Indonesia; Tel: +628562158931; E-mail: vsukmayadi@upi.edu
}

and is predicted that in 2022 the social media users will reach 125 million active users surfing in social media [4].

Of all the social media applications, Instagram, with its feature "Instagram Stories", has now become the public favourite, especially in Indonesia. In 2017, Indonesia became the country with the most significant number of Instagram Stories users, and this too has made Indonesia become the biggest market for Instagram [4]. This phenomenon has become the foundation for the authors in studying the social phenomena among society wherein the application has been widely favoured and how internet application has been able to change people's lifestyle.

Instagram can be described as a photo and video-sharing application which allows the users to take pictures and edit it digitally, and share it to other social networks, including Instagram itself. Instagram can be categorised as social photography application, which is designed for social media 
users in order to be able to interact with other people through both visual and textual footages in the form of photos and motion graphic [5].

Instagram was established in 2010 and by 2016, this application has already been nominated as social media with the rapid growth in popularity. Moreover, by launching a new feature "Instagram Stories", this application has been successful in bolstering its popularity with the user achievement more than 600 million active users around the world [5]. Concerning the popularity of Instagram in Indonesia, Instagram Director for Indonesia [4], stated that the most promising market development for Instagram is in Southeast Asian, with Indonesia as its biggest marketplace. In addition, the director mentioned that the popularity has been emerging in Indonesia because to most of Indonesian, sharing meaningful moments to the public has become a significant culture which has been constructed since a long time ago.

Study on social media, especially Instagram, has intrigued many researchers who work on social culture and communication studies. Based on the index of Google scholar, since 2013, there have been more than 75,800 academic articles related to Instagram studies. Despite being a newestablished company, The rapid increase of Instagram popularity has successfully attracted both users and researchers to study more about this phenomenon of social photography [6 - 8].

Relevant to the current study, several previous studies have contributed to the phenomena being discussed. The first study investigated the teenager's perceptions toward their social attitude in cyberspace, studied by Common Sense Media institution [9]. The study focused on the role of social media in the teenager's life and how the perceptions of teenagers toward their digital activities. This report was based on a survey towards 1,030 teenagers ranging in the age of 13-17 years old.

The study of Common Sense Media found that three out of four teenagers have social networking, and half of the teenagers visit their page every day. Even though some disadvantages may be derived from social media, there was a less significant contribution to social and psychological disorder among teenagers [9]. This finding has contributed to the research literature and extended author's point of view regarding the contribution of social media toward the psychological condition of its users.

In constructing this study, the author refers to the previous research conducted by a number of scholars. First is the study by Lee Eunjji et al. [8] who investigated the motivation of social media users in using Instagram in South Korea. They conducted a comprehensive survey of 212 Instagram users. This survey was utilised to figure out the relation between motivation and attitude of Instagram users in their daily basis. The results found that there were five main social and psychological motives among Instagram users; social interaction, moments, self-expression, avoiding reality, and "sneak peek" motive.

In line with the study mentioned above, other scholars like Amancio [7], Ghazali [10], Sheldon and Bryant [6] conducted a similar study in the Europe, Asia, and the United States respectively. Their study does not only focus on the motivation of Instagram users but also on the relation between the activities done by Instagram users and the degree of their narcissism in social media. The results showed that there is a positive relationship between activities in Instagram and the degree of happiness as well as the "looking cool" attitude of the Instagram users.

Each of the aforementioned studies has a similar theme with what the authors conducted in this paper. The motivation of the users is also one of the variables that were studied in this research. However, in this paper, the authors expanded the analysis by not only investigating the users' motivation but also by emphasising the analysis on the attitude of Instagram users in using Instagram Stories as a current popular feature in the application. In addition, this study investigated how Instagram users manage their self-representation and image through Instagram Stories (Instastory) feature.

\section{DEFINING THE IMPRESSION MANAGEMENT CONCEPT}

In studying the impression management of Instastory users, the author refers to the theory of Impression Management, popularised by Erving Goffman, as the underpinning theory in analysing motivation and impression of the users. Impression management is the manifestation of self-presentation. Selfpresentation is an activity done by specific individuals in order to generate situational definition and social identity for the users, and this situational definition influences the variety of both worthy and unworthy interactions among the actors in the given situation [11].

Goffman [12] also added that when people interact, they want to present a self-image or self-presentation that others will receive. The way they dress up, walk and talk can be used for self-presentation. He called the effort as "Impression management". This assumption does not only occur when we interact in the real world but also now it can be seen from how people interact on social media. He also added that someone interacts because he wants to present a self-image or selfpresentation that will be accepted by others so that he will do impression management to give a particular impression or form a message to others on the front stage. Impression management is both a conscious and subconscious process in which people attempt to influence the perceptions of others by portraying themselves in a manner that creates a good impression. It is about the way someone's look, speak and behave in public or online.

In that way, it can be said that social media users will manage information before it gets published in the form of text or photo entries. They control the influence that will arise from their appearance and regular digital activities on social media [13]. In other words, social media users hope that the audiences will see them the way they want to be seen or perceived through their social media platform.

When a user is uploading some photos on Instagram or other social media platform, he or she tends to portray an appropriate image or attitude so that other people will see the portrayal as the real personality, and in accordance with the expectations of the user as if the user is the main actor of a 
theatrical stage [13]. In other words, it can be assumed the content that social media users publish online is the frontstage of the users to portray the desired characters or roles, while the users' self-reality is kept on the backstage.

Thus, the activities of uploading contents in Instagram can be regarded as one drama stage played by the actors; in this case, Instagram users, through the use of Instagram Stories (Instastory). Based on the descriptions above, this study explored the use of Instastory under two main focuses: 1) users' motivations in using Instastory and 2) the impression management of the users in consciously established their frontstage image on their Instastory.

\section{METHODS}

The authors employed the Phenomenological approach for exploring and understanding meanings derived from problems of social phenomena and or in this case, the Instagram users' online impression management. "Phenomenology is a disciplined, academic effort to understand experience authentically and profoundly toward "phenomena" or appearances of things, or things as they appear in our experience, or the ways we experience things; thus the meanings things have in our experience" [14]. This qualitative research approach involves essential efforts, such as asking questions and conduct some procedures, collecting specific data from participants, analysing data inductively starting from specific themes to general themes, and interpreting the meaning of data [15].

The central premise of the phenomenological approach is based on the assumption that individual perceptions are considered as the foundation for how people experience their day-to-day life in this realm $[16,17]$. Since the study places more emphasis on experienced meaning and values, thus, the phenomenology serves as a well-suited approach for the authors in exploring various unique findings and understanding digital interactions and the philosophical meanings of the Instagram users' online activities.

In collecting the data, the authors conducted open-ended interviews with the participants. The method was chosen because open-ended interviews could provide researchers to gather the participants' experience and elicit relevant information thoroughly $[16,18]$. The open-ended interviews were conducted toward the respondents in a relaxing atmosphere, and the interview stopped when data saturation is reached.

The respondents in this study were 30 social media influencers with age between 20-24 years old and had a range of social media audiences from 1000 to 10.000 followers. The purposive sample was particularly identified to provide insight into the lived experience of those who become the phenomenon [15]. Hence, the selection of the respondents was based on two main reasons. First, a Social Media influencer is a user on social media who has established credibility and density in producing online content on social media [19]. Then, social media influencers have access to a broad audience, and they can persuade others as a result of their online reach and content authenticity [20].

Secondly, The Indonesian Internet Service Providers Association indicated that there are more than 22.3 million social media users aged between 20-24 years and that number can be said to be equivalent to 82 per cent (internet users) of the total digital population in Indonesia [21]. Thus, the authors selected the respondents with the criteria as mentioned above with an assumption that they have the relevant experience and density in using Instagram Stories and could provide reliable information. Furthermore, informants' consent is distributed to obtain the agreement for voluntary participation and the access for the authors to follow the participants' Instagram account.

The findings that the authors collected from the interviews were then reduced and arranged more systematically and important points were highlighted so that a pattern of the participants' conscious motivation in using Instagram stories could be detected as well as the participants' pattern of managing their impressions when using Instagram Stories. Data that has been reduced and classified were then narrated in narrative form after going through the process of member checking and triangulation. As a form of triangulation, the participants online content were observed and then used to confirm what the participants have stated in the interviews. To sum up the procedures, the method of research conducted by the author and the conceptual framework can be seen in the Fig. (1) and Table 1

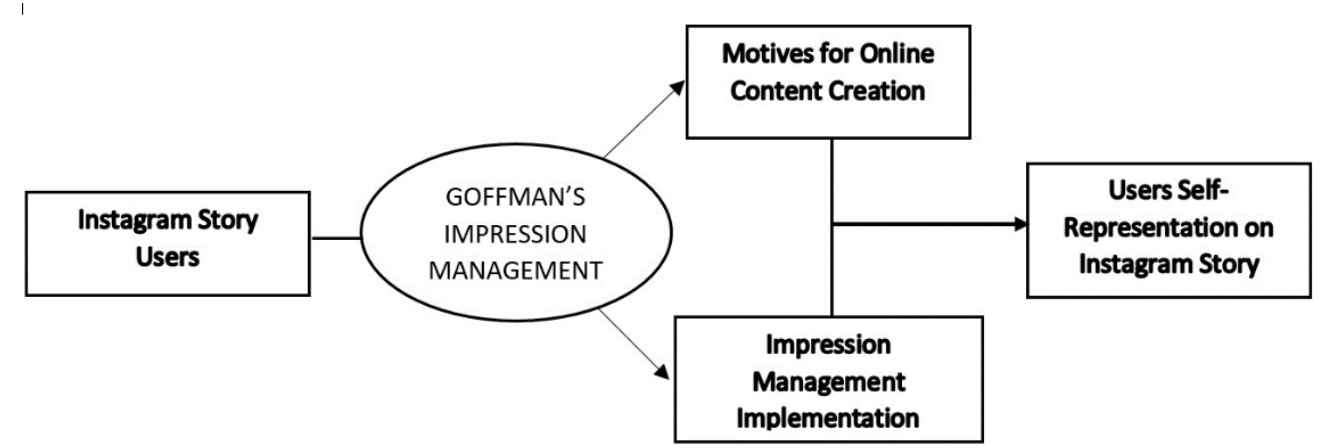

Fig. (1). Conceptual Framework. 
Table 1. Research methodology.

\begin{tabular}{|c|c|c|c|c|}
\hline Research Questions & Participants & Data Collection & Analysis of Procedure & $\begin{array}{c}\text { Location and Research } \\
\text { Duration }\end{array}$ \\
\hline $\begin{array}{l}\text { What motivates the users to engage } \\
\text { actively in using Instagram Stories? }\end{array}$ & \multirow{2}{*}{$\begin{array}{l}30 \text { Instagram } \\
\text { Influencers with a range } \\
\text { of } 1000 \text { to } 10.000 \text { online } \\
\text { followers }\end{array}$} & \multirow[b]{2}{*}{$\begin{array}{l}\text { Open-ended } \\
\text { Interviews }\end{array}$} & \multirow{2}{*}{$\begin{array}{l}\text { Data from the interviews were then } \\
\text { processed into transcription, } \\
\text { categorised, and interpreted based on } \\
\text { impression management theory [11] } \\
\text { and analysed thematically [22] }\end{array}$} & \multirow{2}{*}{$\begin{array}{l}\text { Indonesian Instagram } \\
\text { influencers } \\
\text { The Data was collected } \\
\text { within six months in } 2^{\text {nd }} \\
\text { semester of } 2018\end{array}$} \\
\hline $\begin{array}{l}\text { In what ways do the users apply their } \\
\text { impression management on the } \\
\text { uploaded content? }\end{array}$ & & & & \\
\hline
\end{tabular}

\section{RESULTS AND DISCUSSION}

\subsection{Impression Management Motives}

Social media expansion has been considered as an entity that cannot be separated from our day-to-day life [2, 23]. This nature is also reflected in the use of Instagram applications with its Instagram Stories features that have skyrocketed in popularity. This feature has become something inherent in the lives of its users. Without uploading any photos or contents on Instagram, teenagers would feel like "something is missing in life". Meanwhile, concerning what motivates the Instagram influencers to upload their content on Instagram stories, the results showed that there were at least two categories of motivation; external and internal which then underlie the intensity of Instagram Stories users to update their content frequently.

Internal motivation arises because of the urge to find a place for portraying self-existence, expressing opinions, and building up self-image through social media. Besides, users are also driven by external motivation. This form of external motivation is in the form of exposure to popularity, easiness of use, excellent feature facilities and the influence of the audience (viewers and likes) that make users become "addicted" to continue uploading their stories. In short, the motivation to use Instagram Stories feature can be seen in Table 2 .

Concerning impression management Instagram Stories, the authors found that the informants have various strategies in managing their image, and they consciously manage their image according to what they want. According to Goffman [11], impression management is either a conscious or unconscious process where someone tries to influence the perceptions of others about themselves, other individuals, objects or events; they do it by regulating and controlling information in social interactions. The phenomenon is occurred both in real life and also reflected in the way people interact on social media. This is in line with Cunningham [24] who described that the postings a user uploads to social media would be self-presentations occurring in the front stage, and these are the content that is viewable for public and intentionally communicated by the performer.

Based on Goffman's perspective, social interaction is similar to a drama performance. In a theatrical performance, there are plays, characters, actors, roles, audiences, front stage and rear stage. All are displayed in such a way as to achieve the most significant impact from the audience. The same goes for interactions in social media, based on the interviews and then confirmed by online content observations, the impression management of Instagram Stories users can be classified into several units as described in Table $\mathbf{3}$.

The Instagram Stories provide an opportunity for users to control information for managing impressions in interacting with digital citizens. In referring to Goffman's perspective [8], it can be assumed that individuals using the Instagram Stories feature are social actors, and the timeline screen of the feature is the front stage. An Instagram user plays both roles as the main attraction for the audience and a spectator for the content created by other Instagram Stories users.

Table 2. The motivation of the Instagram Stories users.

\begin{tabular}{|c|c|c|}
\hline $\begin{array}{l}\text { Category of } \\
\text { Motivation }\end{array}$ & Description & Content-Type and Reasons for Uploading the Content \\
\hline \multirow[t]{2}{*}{ Internal Motivation } & $\begin{array}{l}\text { Medium for expressing feelings and } \\
\text { opinions }\end{array}$ & $\begin{array}{l}\text { - Expressing emotion through pictures, video, and words. } \\
\text { - Reviewing current products, places, culinary, and other related themes } \\
\text { - Giving opinions regarding particular issues } \\
\text { - Live report on users highlighted the experience }\end{array}$ \\
\hline & Medium for building up self-existence & $\begin{array}{l}\text { - Portraying users' lifestyle } \\
\text { - Showing talents } \\
\text { - Expecting to be recognized } \\
\text { - Wanted to be acknowledged as an up-to-date person }\end{array}$ \\
\hline \multirow[t]{2}{*}{ External Motivation } & Application popularity & $\begin{array}{l}\text { - The most widely used photo and video-sharing application } \\
\text { - Sophisticated and interesting contents }\end{array}$ \\
\hline & Audience oriented & $\begin{array}{l}\text { - Uploading photos for likes, views, followers and comments } \\
\text { - Having a more peaceful atmosphere compared to the other applications } \\
\text { (Facebook and Twitter) }\end{array}$ \\
\hline
\end{tabular}


Table 3. Impression management of instagram stories users.

\begin{tabular}{|l|l|}
\hline Performance & Instagram Stories \\
\hline Drama & $\begin{array}{l}\text { Interaction flow in Instagram Stories features in the form of pictures, video and peer-to-peer interaction (real-time peer-to-peer } \\
\text { interaction). }\end{array}$ \\
\hline Characters & Instagram Stories users \\
\hline Role & Ways of interaction on a network \\
\hline Audience & People who follow the contents uploaded by certain users \\
\hline Front stage & $\begin{array}{l}\text { Role-playing in the form of captions, comments and audio-visual editing to influence the audience's perception, which will be } \\
\text { represented through the number of views and comments. }\end{array}$ \\
\hline Back Stage & Actual action where the actions of individuals are oriented to what will happen or to what has happened \\
Source: Study Interviews
\end{tabular}

\subsection{Functionality and Contingency as the Primary Motivation}

Based on the data obtained from the respondents, their internal and external sources of motivation lie in the functionality and contingency factors of the Instagram Stories application. Functionality is a media capability designed to facilitate social interactivity [25]. Functionality refers to features that can be used in Instagram Stories. The features provided by Instastory are considered exciting and complete. Based on the results of the interview data analysis conducted by the authors, the Instagram Stories feature is considered more attractive than other similar applications because the content is more sophisticated and complete, as stated by one of the study respondents.

"The reason for choosing Instastory is because the content is more sophisticated than other apps, now they already have Snapchat-like filters; moreover, you can also have fun with the video filters, etc. It has everything, and It's fun as well" R9.

A similar opinion was remarked by other study participants, saying that Instastory is more interesting than other similar applications because of its full features. The respondent stated: "It's fascinating to use Instastory since there are many fun features "R19. The innovations offered by Instagram Stories provide a distinctive attractiveness as a digital interactive medium that can encourage users to install the application.

From the respondents' statements above, it can be considered that since the application offers features that are more advanced, interesting, and yet it is user-friendly, it motivates the users to install and use the app. There is always a significant market for a product that is accessible, useful, credible, desirable and valuable [26].

Aside from the functionality factor, the number of "viewers" is the primary source of motivation that makes users depend so much on the Instagram Stories feature. The word "Viewers" is a term that refers to people who see any Instagram content in their timeline screen. Users of the Instagram Stories consider viewers a vital part, which is very influential in the creation of contents by the users. Online viewers have a contingency effect because the users always look forward to who will see their posts and what kind of response they will get. Contingency can be interpreted as a condition filled with uncertainty about the possibility of getting either good or bad reviews [7]. In this stage, the audience who saw the contents in Instagram Stories makes the users anticipate how the audience would react to the contents.

Getting many viewers are one of the main objectives of the users, and they see it as a form of appreciation from what they have uploaded. This phenomenon was revealed in the statements of several informants below;

"When I upload any content to my timeline, I
always check on the number of viewers who
see my 'stories', and I get a self-satisfaction if
I get a significant number of viewers." R18
"Every time I upload any Instagram stories, I
will check on it constantly, the more viewers I
get, it means that the better response I get from
the audience." R30
"I use Instastory to let people know about my
daily activities, so that people, especially my
followers, would perceive me as an active
person." R2

Some of the statements above indicate that the presence and feedback from the "viewers" gives a sense of satisfaction for Instastory users. The "viewers" are an external motivation that encourages users to continue posting their latest content, and this attitude brings them into a state of dependency or contingency wherein they will continue to be encouraged to update contents and also intensively access the Instastory feature.

This phenomenon is similar to a study conducted by Zak [27], which investigates the level of oxytocin hormone (the love hormone) toward some of the respondents when they are active on social media. The results of the study were quite astonishing because, in the first 10 minutes of the respondent's activities on Instagram, their oxytocin hormone increased by $13.2 \%$. The record is similar to the levels of the oxytocin hormone of a person who is getting married or to a toddler who feels comfortable and stops crying when they are on their mother's embrace [28]. Additionally, when the respondents are active on social media, the stress hormone level is reduced by $14.9 \%$ [28]. The results of these studies indirectly support the findings of this study regarding what may cause someone being so hypnotized and addicted to social media, including using Instagram stories. 


\subsection{Digital Storytelling with Instagram Stories}

Based on the interviews and online confirmation, Instagram Story posts and settings have a distinctive narrative style, which then directs the users to speak in a pattern built within the application. Concerning the phenomena, Amancio [7] reveals that online narratives are defined in different ways, through different features and depending on who uploads them. However, the Internet has a significant influence. Internet platforms, such as Instagram can bring up a kind of latent rule that can direct how users communicate and be able to explain what is interesting to do and what is not for users. In other words, whether or not a post is neat or not is also governed by the features in the Instagram Stories application.

One of the narrative styles framed by the Instagram application is emotion. Instagram Stories seems to direct users to embed emotions into each content. This emotional element, however, is difficult to express in the cyberspace. Therefore, the expression that the users want to convey into their story depends on what features the Instagram application provides that can translate the intended emotions of the users [19]. It is common to see Instagram Stories users share personal emotional moments, closeness with friends, family, and pets, for example, and repeatedly use various "emoji" logos to express their real feelings.

This personal touch is part of "digital storytelling", to give the audience a real experience of the users' stories (as a content contributor). In this digital era, the realm of personal feeling has become part of the Internet, because Internet technology allows users to express themselves, to develop relationships with each other, to create, and to adjust content in various ways to be able to give the best storytelling $[6,29]$. This personal touch in uploading the Instagram Stories are also illustrated in the results of the authors' interview with the respondents such as the quote below;

"If I want to post something, I have to use captions and emojis, even doodles. In that way, my emotional expression is also seen by my viewers so that they will know my emotional state..." $\mathbf{R 2}$.

In line with the previous statement, the other respondents also added that to create a good story, we need ideas and time so that the emotions and stories told can have maximum impact as desired.

"Before posting any content, we must consider first about what kind of filters and emojis we must use, the language we are going to use: in English or Indonesian, and do we need to put the location? Everything must be thought thoroughly first so that viewers can feel it or at least become attracted to our content" R17.

This personal aspect is also connected with the function of the internet itself as a community builder. Online technology can bring together various individuals to communicate with each other so that individuals who use this technology can share their thoughts, concerns, and opinions [29].

The other dominant storytelling style in Instagram Stories is a casual and humorous style atmosphere. All respondents acknowledged that Instagram Stories were far more peaceful and relaxed than other popular applications that were often filled with political debates and abuse. This finding is in line with the authors' previous research in which social media Facebook and Twitter became two applications filled with the content of political debate and tended to make users bored [30].

Instastory users enjoy light humour, "out of the box" opinions, and entertaining content that is hard to find in mainstream media, such as television and newspapers [7]. Humorous content and a relaxed language style are straightforward to find in Instagram Stories. One of the great touches of humour that support digital storytelling is the "meme" phenomenon. Instagram Stories users generally combine video and images and sometimes convert it into "gif" format to insert transitions, and it is often a combination of writing (caption) with funny photos and graphic effects. Related to this finding, Couldry [31] emphasises that the mixture of text, which makes a visual presentation of a narrative by combining other materials, has a different meaning far above the textual content.

The use of the aforementioned elements not only constructs narratives when displayed together in a single feature but also makes the stories as if it were real to the user who saw it at the same time. In other words, digital storytelling requires certain elements to present their stories in the most reasonable and exciting way for the audience.

\subsection{Instagram Stories as a Representation of Self-identity and Social Status}

In using Instagram Stories, users tend to represent themselves through the content on Instagram Stories. Respondents felt that the way users convey impressions in each upload has its characteristic they want to show to the viewers. These characteristics are seen from the similarity of themes in every instastory uploads, such as by being aesthetic, telling about culinary or traveling. Respondents felt that if they have their uniqueness or distinctive characteristic in each upload, then it would probably become something interesting to see by the viewer and would cause a positive response later.

This uniqueness can be reflected in the statements of several respondents during the interview session: "I like to eat, ... so I like to update my culinary experience on the instastory, surprisingly, people like to see it, that is why I keep updating culinary-based content" $\mathbf{R 3 0}$. Other respondents also expressed their opinion about their content uniqueness, "most of the contents in my Instastory are my singing records so that people will know that I love singing'R15. There are even respondents who have a scary Instastory style to attract the attention of the viewers as stated below;

"I want my Instastory contents to have a specific characteristic so that my viewers are 
happy to see it, such as horror stories or item or food reviews because usually many are curious about the horror stories I made" R19.

The consistency of themes in each upload is a part of the user's primary strategy in managing impressions for the audiences who follow the account. Therefore, this thematic style is what makes Instagram Stories a representation of the user's social status.

The interview results indicate that users use the Instagram story to show their social status. The respondents felt that uploading their whereabouts in a specific place would create another impression on them in the eye of the audiences. If they upload content that contains popular places, their status will also be boosted as a tech-savvy and up-to-date person.

This finding is reflected in the statement of a respondent as follows; "If I go to a shopping mall, I like to update about it, but if I go to a mainstream destination, I don't think it will look that impressive for the viewers "R22. The impression of being in a high social status is essential to this respondent since it is the image she/he wants to portray. Other respondents also shared a similar feeling;

\begin{abstract}
"I usually only talk about popular cafes, I even barely come to typical cafes; actually, I made it that way so that the viewers will not think of me as an old-fashioned person and moreover, I could also promote the café" $\mathbf{R} 13$.
\end{abstract}

The statement above shows that updating about famous cafes or places visits can contribute to the impression of different social statuses and are considered more valuable than uploading other activities. In other words, each story Instagram user is motivated to make content customisation in order to fulfil the image they want to display. According to Goffman [32], this attitude is known as a self-defence strategy from something he does not want bis audience to see (Defensive measures). Defensive measures strategies that are commonly applied by users of the Instagram Stories are by overemphasising information (over communication) or hiding information (under communication). Therefore, it is common if an Instagram Stories user will spend time sorting out and editing information or stories that will be uploaded to get the maximum impact.

For this reason, displaying distinctiveness is one way for Instagram Stories users to manage the impressions. Although Instagram Stories only contain a small portion of the user's daily life, that is precisely the regular life that users want to portray to their audience when they upload content on Instagram Stories.

\subsection{Content Consistency for Self-Branding}

One of the impression management strategies found in this study has consistency in terms of theme, caption and time when uploading photos or videos. This strategy aims to make the impression expected by uploaders well conveyed to the viewers. One of the respondents said that he manages the impression he wants to convey by forming a pattern or adjust the suitability for the instastory contents that was made. The respondent's statement is as follows:

" I create a specific pattern in my instastory, the theme is not far from my hobbies and what I like, so every time I update on Instagram, it's always about cooking and food, and if I go for a culinary trip, the caption must also be written carefully, sometimes use English or Indonesian, or mixed between them " $\mathbf{R 2}$.

R2's opinion is in line with other respondents who said that the habit of uploading singing content is one way of managing impressions. Two other respondents revealed similar things;

\begin{abstract}
"I once updated about my travelling activities on my Instastory; apparently there were many people who asked for more trips, so I am happy to upload more about my travelling" R28.
\end{abstract}

"I love culinary, so I like to update about culinary on my Instastory, and I also created fun captions; Fortunately people love to see it, so upload more contents about culinary" R30.

Related to the statements above, consistency serves as an image amplifier - the more consistent a user in creating the theme, the stronger the image that will be highlighted. As an illustration, if an Instagram Stories user wants to create their impressions positively, he or she will not upload deviant and controversial activities to avoid negative impressions about them. Besides, sorting the Caption of the contents is also a paramount factor because captions are "the seasoning" that can emphasise and direct the attention of the viewers. In this case, the viewers will recognise the self-branding that user wanted to portray and habits that are raised by the user and the images that appear will stick in the minds of the viewers [33].

Sheridan [34] strengthen these findings by emphasising on the importance of consistency in creating brands and selling power both for individuals and groups. The more consistent a user in shaping the theme, the more familiar the viewers will be with the branding of the individual who uploads it. Moreover, in shaping the theme consistency, the use of captions is essential both as an image amplifier and as a medium to deliver messages. In summary, here are the patterns of managing the impressions of Instagram Stories users which can be seen simply in Table 4. 
Table 4. Motivation and the construction of impression management for instagram stories users.

\begin{tabular}{|l|l|}
\hline \multicolumn{1}{|c|}{ Motivation on Impression Management } & \multicolumn{1}{c|}{ The Construction on Impression Management } \\
\hline Appraisal towards functions and application Instagram stories & Storytelling by using emotion elements and casual delivery \\
\hline Contingency effect which makes users addicted & Representation of self-branding and social status (Potential Social Image) \\
\hline The right media to tell stories online & Consistency of upload patterns as an image builder \\
\hline Incompatibility between the current image and expected image & Limit the posting output (only uploads that are considered to support self-branding) \\
\hline
\end{tabular}

\section{CONCLUSION}

The popularity of Instagram with the Instagram Stories feature has indeed become a phenomenon in Indonesia. It is not surprising that Instagram Stories has become one of the main tools for managing the impression of digital citizens of social media users. In conclusion, the study indicates that the primary motivation for using Instagram Stories is in terms of renewal, convenience, atmosphere in the application and encouragement of self-existence through interaction with the "viewers". Besides, users use the Instagram Stories feature as a medium for managing their impressions.

Instagram Stories, is a storytelling media that delivers the digital story wherein each upload contains the reality that the user wants to bring up about. Through emotional elements (emoticons, doodles, captions, filters and doodles), as well as humorous and light nuances of delivery, users of this application try to invite viewers to enter and feel the image contents drawn by the users. Overall, the pattern of managing user impressions can be seen from the way the users upload their contents. Users upload their stories consistently with distinctiveness through captions and content to produce the maximum impact. The impact referred to this case can be in the form of self-satisfaction, the number of viewers, positive feedback from the viewers, and constructing the best image of the content creator (users).

\section{ETHICS APPROVAL AND CONSENT TO PARTICIPATE}

Not applicable.

\section{HUMAN AND ANIMAL RIGHTS}

No animals/humans used for studies that are the basis of this research.

\section{CONSENT FOR PUBLICATION}

The authors obtained the written informed consent from each interview participant.

\section{FUNDING}

None.

\section{CONFLICT OF INTEREST}

The authors declare no conflict of interest, financial or otherwise.

\section{ACKNOWLEDGEMENTS}

We would like to show our gratitude to Mr. Dante Darmawangsa for providing insight and expertise that assisted this study. We are also grateful to TOPSYJ editors and reviewers for their insights on the improvement of the paper.

\section{REFERENCES}

[1] Statista Leading social networks worldwide as of January 2018, ranked by the number of active users (in millions), wwwstatistacom 2018. [Online]. Available: http://www.statista.com/statistics/272014/ globalsocial-networks-ranked-by-number-of-users/

[2] Yahya AH, Azizam AA, Sidek JJ. Social media and democratization: A new form of democratic transition 2015; 6 .

[3] Bollier S. Voting in the 'world's social media capital Al Jazeera 2014 [Online]. Available: https://www.aljazeera.com/indepth/ features/2014/07/voting-worlds-social-mediacapital-2014725397392826.html

[4] Yosephine L. Indonesia Instagram's biggest market in the Asia Pacific The Jakarta Post 2017. Jakarta, 26-Jul-2017.

[5] Harris M. Marketing with instagram, the fastest growing social platform! The Medium Well 2017. [Online]. Available: http:// mediumwell.com/marketing-instagram/. [Accessed: 20-Jan-2018].

[6] Sheldon P, Bryant K. Instagram: Motives for its use and relationship to narcissism and contextual age. Comput Human Behav 2016; 58: 89-97.

[http://dx.doi.org/10.1016/j.chb.2015.12.059]

[7] Amâncio M. ' Put it in your Story ': Digital storytelling in instagram and snapchat stories. Uppsala Universitet 2017.

[8] Lee E, Lee JA, Moon JH, Sung Y. Pictures speak louder than words: motivations for using instagram. Cyberpsychol Behav Soc Netw 2015; 18(9): 552-6.

[http://dx.doi.org/10.1089/cyber.2015.0157] [PMID: 26348817]

[9] Rideout V. Measuring time spent with media: The common sense census of media use by us 8 to 18 -year-olds. J Child Media 2016; 10(1): 138-44.

[http://dx.doi.org/10.1080/17482798.2016.1129808]

[10] Ghazali AHA, et al. Potential personality traits that explain cyberbullying among youth in malaysia. Int J Acad Res Bus Soc Sci 2017; 6(12): 741-9.

[11] Goffman E. The presentation of self. 1st ed. Edinburgh: University of Edinburgh 1956.

[12] Longhofer W. Social theory re-wired. 2016 [http://dx.doi.org/10.4324/9781315775357]

[13] Tashmin N. Art of impression management on social media. World Sci News 2016; 30: 89-102.

[14] Smith DW. "Phenomenology', the stanford encyclopedia of Philosophy," stanford encyclopedia of philosophy metaphysics research lab. Stanford University 2018.

[15] Creswell JW. Research design: Qualitative. Quantitative, and Mixed Methods Approaches 2013.

[16] Mulyana D. Metodologi penelitian kualitatif: paradigma baru ilmu komunikasi dan ilmu sosial lainnya 2001.

[17] Payne SM. A phenomenological inquiry of media literacy of middle school students enrolled in a north texas middle school sara m payne, ba, mls dissertation prepared for the degree of doctor of philosophy december 2008 approved : George s larke-walsh, minor p. : University of North Texas 2008.

[18] Bleich E, Pekkanen R. How to report interview dataInterview Research in Political Science. 2014; pp. 84-106.

[19] Ge J, Gretzel U. Emoji rhetoric: A social media influencer perspective. J Mark Manage 2018.

[http://dx.doi.org/10.1080/0267257X.2018.1483960]

[20] Freberg K, Graham K, McGaughey K, Freberg LA. Who are the social media influencers? A study of public perceptions of personality. Public Relat Rev 2011.

[http://dx.doi.org/10.1016/j.pubrev.2010.11.001]

[21] Indonesia Internet Service Provider Association. Jakarta: Infografis Penetrasi \& Perilaku Pengguna Internet Indonesia 2018. 
[22] M. B. \& H. A. M. Miles. Qualitative data analysis: An expanded sourcebook. 1996.

[23] Potter WJ. Guidelines for media literacy interventions in the digital age. Media Res 2014

[24] Cunningham C. Social networking and impression management: Selfpresentation in the digital age. 1st ed. Plymouth: Lexington Books 2013.

[25] Guillory J, Sundar SS. Can interactivity in corporate websites influence public perceptions of organizations? the annual meeting of the International Communication Association.

[26] Boswell W. Why people uninstall apps 2013. https://www. forbes.com/sites/ciocentral/2013/11/21/why-people-uninstallapps/\#2352eeef4be4

[27] Zak PJ, Stanton AA, Ahmadi S. Oxytocin increases generosity in humans. PLoS One 2007; 2(11)e1128 [http://dx.doi.org/10.1371/journal.pone.0001128] [PMID: 17987115]

[28] Lin P-Y, Grewal NS, Morin C, Johnson WD, Zak PJ. Oxytocin increases the influence of public service advertisements. PLoS One $2013 ; 8(2)$ e56934 [http://dx.doi.org/10.1371/journal.pone.0056934] [PMID: 23460821]

[29] Handler Miller C. digital storytelling: A creator's guide to interactive entertainment. Burlington: Elsevier Inc. 2004; Vol. 53.

[30] Sukmayadi V, Effendi R. Social media emotion in politics: An indonesian case study of political environment on facebook IOP Conf Ser Earth Environ Sci. vol. 145: 012009.

[http://dx.doi.org/10.1088/1755-1315/145/1/012009]

[31] Couldry N. Mediatization or mediation? Alternative understandings of the emergent space of digital storytelling. New Media Soc 2008. [http://dx.doi.org/10.1177/1461444808089414]

[32] Hogan B. The presentation of self in the age of social media: Distinguishing performances and exhibitions online. Bull Sci Technol Soc 2010; 30(6): 377-86.

[http://dx.doi.org/10.1177/0270467610385893]

[33] Maryani E, Adiprasetio J. Magdalene.co Sebagai Media Advokasi Perempuan. J ILMU Komun 2017; 14(1): 111.

[http://dx.doi.org/10.24002/jik.v14i1.836]

[34] Sheridan T A. Malevolent managers: Insights using executive impression management. Routledge 2017.

[http://dx.doi.org/10.4324/9781315562704]

C 2019 Sukmayadi and Yahya.

This is an open access article distributed under the terms of the Creative Commons Attribution 4.0 International Public License (CC-BY 4.0), a copy of which is available at: https://creativecommons.org/licenses/by/4.0/legalcode. This license permits unrestricted use, distribution, and reproduction in any medium, provided the original author and source are credited. 